\title{
"O mundo não pode ser dividido em coxinhas e petralhas": a construção de posicionamentos em torno do impeachment
}

Bruno Deusdará*

Paula Gesteira**

\section{Resumo}

O processo de impeachment efetuado em 2016 convoca as diversas áreas do saber à reflexão crítica e à problematização de sua emergência e consolidação. Com o intuito de fornecer uma contribuição à leitura desse processo, interrogamos a construção de posicionamentos discursivos em torno desse evento que altera significativamente os contornos da história contemporânea brasileira. Como quadro teórico, recorremos à análise do discurso de base enunciativa, cujo foco recai sobre 0 modo de articulação de pistas linguístico-discursivas na reconstituição dos embates a partir dos quais os posicionamentos são construídos. Em nossas análises, investigamos dois artigos de opinião publicados em veículo de grande circulação no país, antes da votação final no Senado Federal. Como resultados, destacamos as diferentes linhas que constituem os posicionamentos em jogo, indicando que, do lado contrário, encontram-se perspectivas que promovem diálogo entre diferentes pontos de vista e, do lado favorável, concentram-se as oposições unilaterais.

Palavras-chave: Impeachment. Golpe. Posicionamento. Análise do discurso.

\section{Considerações iniciais}

No presente artigo, investigamos construção de posicionamentos discursivos diversos no debate em torno de um evento recente da história republicana brasileira, a saber o processo de impeachment, cuja duração compreendeu o período entre 2 de dezembro de 2015 , com a aceitação, pelo então presidente da Câmara dos Deputados, da denúncia de crime de responsabilidade, e 31 de agosto de 2016, com a decisão do Senado Federal, pela cassação do mandato da presidenta Dilma Rousseff.

\footnotetext{
Doutor em Psicologia Social (Uerj). Professor Adjunto do Departamento de Estudos da Linguagem e dos Programas de Pós-graduação em Letras e em Letras e Linguística da Universidade do Estado do Rio de Janeiro. Os resultados desta pesquisa contaram com financiamento do Programa Jovem Cientista do Nosso Estado, vinculado à Fundação de Amparo à Pesquisa do Estado do Rio de Janeiro (Faperj) e Prociência (Uerj/ Faperj). E-mail: brunodeusdara@gmail.com

* Mestre em Letras, com área de concentração em Linguística (Uerj). Licenciada em Português/Inglês (Uerj). E-mail: gesteira.paula@yahoo.com.br
}

Data de submissão: abr. 2018 - Data de aceite: jun. 2018 http://dx.doi.org/10.5335/rdes.v14i2.8052 
Pela abrangência cronológica e complexidade na composição de diferentes redes discursivas que constituem o evento, optamos por recorte bastante específico do material a ser analisado, cujos critérios de seleção serão mais detidamente discutidos em seção posterior. Por ora, cabe apenas destacar que analisaremos dois artigos de opinião, publicados em jornais de grande circulação no país (Folha de São Paulo e Estado de Minas), em data anterior à aprovação do relatório na Comissão Especial da Câmara dos Deputados, que começava a delinear a conformação de maiorias para a instauração do processo. Desse modo, interessa-nos compreender que contornos são conferidos ao debate público veiculado pelas grandes empresas de comunicação do país, em momento decisivo para nossa história recente.

As implicações que nos vinculam a essa temática se constituem a partir de linhas diversas - linhas de força que nos atravessam e constituem a instauração, marcada historicamente, de sentidos na e pela linguagem. De um lado, estamos implicados por um interesse geral a respeito das diferentes lutas empreendidas, que remetem aos antecedentes desse processo e recaem sobre desdobramentos recentes, que ampliam a fragilização dos direitos sociais, com os contingenciamentos no financiamento de políticas públicas de saúde, educação e previdência social e intensificam margens de precarização da vida comum, restringindo o acesso aos empregos formais, com alterações na legislação vigente, e compressão das políticas de moradia, mobilidade, entre outras. De outro, manifestamos o desejo de afirmar a condição de cientista social do profissional que pratica Análise do Discurso (AD), entendendo que tal afirmação passa necessariamente por um debate filosófico a respeito da concepção de linguagem - a consideração da linguagem como um plano de intervenção sobre o real.

Rejeitando a tese de que a linguagem apenas reapresentaria eventos que ocorreriam no seu exterior, consideramos o verbal como uma dimensão produtora de realidade. Em evidente contraposição à corrente dissociação entre "discurso" e "prática", que encontra larga ressonância no senso comum, entendemos que a tomada da palavra sempre fornece um modo de ler o entorno no qual nos inscrevemos. A leitura que fazemos do que nos ocorre e vincula ao mundo integra nossos modos de pensar, sentir e agir sobre ele. Acrescentamos a isso uma outra questão: para falar sobre o mundo, é preciso, em alguma medida, construir um lugar a partir do qual seja possível tomar a palavra. Em outras palavras, "a enunciação não é uma cena ilusória onde seriam ditos conteúdos elaborados em outro lugar, mas um dispositivo constitutivo da construção do sentido e dos sujeitos que aí se reconhecem" (MAINGUENEAU, 1997, p. 50). Nessa direção, parece-nos bastante produtiva a hipótese de uma semântica global, segundo a qual não se 
poderia localizar em um único aspecto do texto o fundamento para a produção de sentidos. De acordo com o autor, não seria possível, por exemplo, indicar o plano do conteúdo como pretensamente central na construção dos significados na interação verbal. A intertextualidade, o vocabulário, o estatuto entre os enunciadores, o modo de coesão intradiscursiva, entre outros dispositivos, interagem e constroem os posicionamentos a partir dos quais os discursos se constroem e estabelecem em relação com outros discursos, assumidos como contrários ao que sustentam. A isso, acrescenta-se um outro aspecto fundamental, a relação entre os discursos e as instituições, em torno das quais se vinculam, "a passagem de um discurso a outro é acompanhada de uma mudança na estrutura e no funcionamento dos grupos que gerem esses discursos" (MAINGUENEAU, 2005, p. 125).

Essa orientação discursiva tem sido articulada à tradição institucionalista francesa procurando não apenas a política como um tema ou instituição de origem dos discursos e avançando em uma "dimensão política" presente em todos os atos de linguagem. Acolhendo as diferentes pistas linguístico-discursivas que integram a textualidade, buscamos reconstruir os embates em torno dos quais os posicionamentos em jogo são construídos. A partir dessa articulação, tem sido possível explorar uma "dimensão política" dos textos, em geral, definida como "o sistema de alianças construído entre diferentes vozes apreensíveis em um texto, sendo tal sistema responsável por conferir a essas vozes maior ou menor grau de aderência ao plano instituído" (ROCHA; DEUSDARÁ, 2017, p. 109).

No presente artigo, propomos um ensaio de análise dessa articulação, iniciando pela explicitação de conceitos que constituem nossa perspectiva discursiva.

\section{"Os ânimos estão acirrados, sem dúvida": interdiscursividade e prática discursiva na construção de embates}

Neste item, apresentamos os conceitos que fundamentam as análises propostas, procurando, simultaneamente, caracterizar essa prática em $\mathrm{AD}$ que assume novos contornos a partir dos anos 1980, com ancoragem na perspectiva enunciativa. Já na constituição da frase que dá título a este item, um procedimento enunciativo - o da captação - ilustra, de modo curioso, o dispositivo acionado. $\mathrm{Na}$ frase, sintetiza-se uma ideia que parece ser, em certa medida, partilhada pelos enunciadores de ambos os textos: a tematização do esgarçamento do tecido social em torno do debate político. A título de exemplo, observaríamos que, no texto 1 , a frase de abertura sugere uma interlocução com tal ponto de vista. Em "Faço uma apologia ao diálogo", subentende-se uma certa escassez da interlocução entre 
diferentes posições. Se, no plano do conteúdo, há razões para o estabelecimento desse ponto de aproximação na discussão realizada, tal aproximação não resiste às considerações a respeito dos "modos de dizer" reivindicados pelos arranjos linguístico-discursivos que ganham corpo nos diferentes textos.

A partir do exemplo tematizado, demonstramos a formulação da hipótese da teoria que organiza a proposta de uma semântica global, que "não apreende o discurso privilegiando tal ou tal de seus 'planos', mas integrando-os a todos, tanto na ordem do enunciado quanto na da enunciação" (MAINGUENEAU, 2005, p. 79). Nessa direção, não seria possível considerar uma espécie de primazia dos conteúdos como pretensa expressão, na superfície linguística, de um "fundo", exterior à linguagem. "Não pode haver fundo, 'arquitetura' do discurso, mas um sistema que investe o discurso na multiplicidade de suas dimensões" (MAINGUENEAU, 2005, p. 80). Sem dúvida, esse projeto de crítica ao conteudismo é um gesto fundante das diferentes tendências em $\mathrm{AD}$, tal como já registraram Orlandi (2005), Possenti (2003), Rocha e Deusdará (2005, 2006, 2011).

Com efeito, a perspectiva discursiva adotada centra-se no primado do interdiscurso como um princípio teórico organizador, cuja inspiração remontará aos trabalhos de M. Bakhtin, que, naquele momento, o analista do discurso conhecera por intermédio dos trabalhos de T. Todorov e J. Authier-Revuz. Para
Bakhtin (2011), a ocorrência de enunciados, em circunstâncias concretas de uso, realiza-se constantemente em remissão a outros enunciados. Na série que se configura, cada enunciado constrói sentido a partir da relação que estabelece com outros enunciados, definindo relações que podem manifestar concordância, oposição, distanciamento aparente, entre outros. Segundo o autor, um enunciado, tomado apenas em sua configuração interna, perde o estatuto de enunciado e se torna "frase" de uma língua.

Esse primado, em formulação semelhante à da heterogeneidade constitutiva de Authier-Revuz, será desdobrado na seguinte tríade: i) universo discursivo, que reúne "o conjunto de formações discursivas de todos os tipos que interagem numa conjuntura dada" (MAINGUENEAU, 2005, p. 35); ii) campo discursivo, definido como "um conjunto de formações discursivas que se encontram em concorrência, delimitando-se reciprocamente em uma região do universo discursivo" (MAINGUENEAU, 2005, p. 35), e; iii) espaço discursivo, delimitados como "subconjuntos de formações discursivas que o analista julga relevante para seu propósito colocar em relação" (MAINGUENEAU, 2005, p. 37).

Mesmo que não se mostre como tal, mesmo que pretenda fazer ver a "presença de um 'eu", o discurso é, de acordo com essa perspectiva teórica, marcado pela presença constitutiva da alteridade. Nessa direção, Maingueneau (2007) propõe a hipótese de que o interdiscurso 
precede o discurso. Qualquer enunciado se delimita a partir da relação que estabelece com outros enunciados, o que implica dizer que o investimento na interdiscursividade marca o interesse do analista.

Com efeito, tal perspectiva instaura, no campo da linguagem, uma recusa do primado da identidade de um discurso sobre a relação que manteria com a exterioridade. A identidade, desse modo, é fundada na interdiscursividade, cuja tensão permanente reelabora os discursos a partir de sua interdelimitação com sua exterioridade.

[...] o caráter constitutivo da relação interdiscursiva faz aparecer a interação semântica entre os discursos como um processo de tradução, de interincompreensão regrada. Cada um conduz o Outro em seu fechamento, traduzindo seus enunciados nas categorias do Mesmo e, assim, sua relação com esse Outro se dá sob a forma do 'simulacro' que dele constrói (MAINGUENEAU, 2007).

Uma consequência bastante evidente desse tipo de perspectiva reside em compreender o falante não o reduzindo ao indivíduo que reconhece mecanismos linguísticos de composição de frase e itens lexicais sobre os quais esses mecanismos incidem. Produzir enunciados supõe o reconhecimento de um certo horizonte formado por sua inscrição em comunidades de produção e circulação de textos, uma "massa" a partir da qual os enunciados encontram-se em constante reelaboração.

Outro efeito importante de se assumir o interdiscurso como um primado organizador de nossa compreensão das práticas de linguagem reside em perceber que um posicionamento nunca se deixa apreender por outro a partir de seus próprios valores e sentidos, mas por intermédio dos contornos que o outro estabelece para sua própria compreensão. Em outras palavras, a relação entre o Mesmo e o Outro se dá sob a forma de simulacro.

Essas comunidades de produção e circulação de textos se configuram, portanto, fundadas em posicionamentos diversos. Esses posicionamentos organizam, simultaneamente, as regularidades a partir das quais é possível enunciar e aquelas que "filtram" a compreensão de seu outro: "não há dissociação entre o fato de enunciar em conformidade com as regras de sua própria formação discursiva e de 'não compreender' o sentido dos enunciados do Outro" (MAINGUENEAU, 2005, p. 103).

Como se observa em tal formulação do contato regrado entre formações discursivas, o autor sustenta que uma formação discursiva elabora os modos de compreensão de seu Outro com base nas regularidades sobre as quais se constitui. A complexidade de tal reflexão produz, de imediato, a ruptura com uma dimensão de interação que se constituiria entre um "eu" e um "outro", enquanto tais. Tem-se contato com os sentidos produzidos por outra formação discursiva com base numa espécie de "tradução" que se operaria, definida como "regras de passagem de uma interpretação a outra, sem tocar na estabilidade do significante linguístico" (MAINGUENEAU, 2005, p. 104). 
$\mathrm{O}$ autor afirma que, no interior de uma mesma língua, existem zonas de interincompreensão, por isso falamos em "discurso" e "tradução". Podemos entender tradução, nesse contexto, como um mecanismo de reformulação/reapropriação dos enunciados. Contudo, o enunciador não interpreta seu discurso, ou seja, não é a partir de si mesmo que os enunciados serão compreendidos, mas por um privilégio reservado a uma instância exterior, ao Outro. Como afirma o autor, “a 'tradução' que nos interessa aqui é um mecanismo necessário e regular, ligado à constituição de formações discursivas que remetem, para além delas mesmas, a descontinuidades sócio-históricas irredutíveis" (MAINGUENEAU, 2005, p. 105).

Associada a essa ideia, encontramos, portanto, o conceito de interincompreensão. Dito desse modo, torna-se necessário salientar que a compreensão dos sentidos de uma formação por outra não se fundaria na ilusória promessa de uma interpretação consensual, mas antes numa mediação sempre tensa, fundada em uma interincompreensão.

A interincompreensão não é necessariamente um mal-entendido. E, exatamente por essa razão, não espera ser desfeita por um ato de vontade. Possenti (2009) elucida que interincompreensão "não tem nada a ver com má vontade ou incompetência dos adversários mútuos"; mas, sim, que "todos que têm acesso a um discurso 'de fora' compreendem-no 'erradamente' - porque o compreendem a partir de sua própria posição e não da posição dos enunciadores daquele discurso" (POSSENTI, 2009, p. 24).

Embora o referido conceito seja aqui apresentado pelos efeitos que constrói no campo dos discursos, o horizonte filosófico que se pode antever nele é igualmente produtivo. Considerando-se a importância da interincompreensão, rejeita-se a pressuposição de que os sentidos poderiam ser estabelecidos por um acordo prévio entre os falantes, algo que poderia ser pretensamente atribuído a uma espécie de difusa natureza humana pré-disposta aos pactos. Trata-se de uma pressuposição que, em alguma medida, já se encontrava no esquema emissor-mensagem-destinatário - cujo impacto ainda hoje é reconhecido em abordagens teóricas diversas:

[...] para discursos que não podem ter pretensão à consistência e à adequação empírica, é necessário haver-se com universos semânticos submetidos a uma economia completamente diferente, cujas noções são construídas sobre um intertexto flutuante e que não acedem jamais à univocidade (MAINGUENEAU, 2005, p. 106).

Sustentando a impossibilidade de os discursos confluírem para um horizonte de redução à Unidade, outro conceito é estabelecido pelo autor é o de polêmica, cujos contornos teóricos investidos dissociam-se do estabelecido pelo senso comum. Polêmica não representa aqui uma contenda hostil. Vinculada ao primado do interdiscurso, a emergência da definição de polêmica proposta se funda na seguinte articulação: 
De fato, se é uma conquista importante poder pensar o caráter interdiscursivo de enunciados que não apresentam nenhuma marca visível de relação com outro enunciado, não se pode negar que a interpelação do adversário em uma troca regrada, a polêmica, representa um gesto capital, que cria situações irreversíveis, provoca múltiplos encadeamentos e enunciações novas (MAINGUENEAU, 2005, p. 112).

Maingueneau (2005) admite que a noção de polêmica pode ser simplificada se associada à ideia de "ameaças". Segundo ele, não cabe saber quem defende ou quem ataca, a ameaça é recíproca e generalizada até que se institua um novo discurso. E mesmo que os protagonistas queiram evitar o conflito, será em vão, pois eles estão desde sempre envolvidos nele. E se a incompatibilidade for radical e global, o conflito pode a priori recair sobre qualquer ponto.

O autor ressalta que polêmica não se refere apenas à ameaça. "Polemizar é, sobretudo, apanhar publicamente em erro, colocar o adversário em situação de infração em relação a uma lei que se impõe como incontestável" (MAINGUENEAU, 2005. p.114). Nesse caso, trata-se de mostrar ao adversário que ele está violando as regras do jogo, mentindo, usando citações inexatas, sendo incompetente, etc.

Na polêmica, é a convergência que prevalece sobre a divergência, já que o desacordo supõe acordo sobre "um conjunto ideológico comum". Para haver polêmica, é necessário haver "relações explícitas entre duas formações discursivas".
A polêmica não é simplesmente uma relação de controvérsia (esta é apenas um de seus elementos): só se pode falar em polêmica quando um discurso faz menção explícita a outro; ou seja, a polêmica existe quando um discurso interpela o adversário, gerando uma cadeia de enunciações. Se não há nenhuma marca visível de relação com outro enunciado, não há polêmica (NARZETTI, 2001, p. 05).

A polêmica se fundamenta com base na convicção de que existe um código que supera os discursos antagônicos, ou seja, que para além do conflito uma instância outra seja capaz de sustentar outra posição que não seja uma posição dicotômica. Por exemplo, o juiz e o árbitro são profissões que não fogem a dicotomia do sim ou não, do certo ou errado.

É importante ressaltar que a polêmica acontece dentro de sua própria formação discursiva. Não é possível que ela se estabeleça num afrontamento de dois universos incompatíveis. Portanto, falar de convencimento não parece adequado, pois não se pode mostrar uma exterioridade entre o código de referência e as interpretações dos discursos que se fundam nele (MAINGUENEAU, 2005, p.117). O convencimento só acontece quando o discurso enunciado coincide com o que já se passava pela nossa cabeça, esse texto seria apenas uma explicação ou uma repetição.

Maingueneau (2005) afirma que a polêmica é necessária porque, sem essa relação com o Outro, a identidade do discurso correria o risco de desfazer-se. Essa razão mascara a vulnerabilidade do discurso. O discurso não tem razão 
a não ser na medida em que se entende que ele pode ser ameaçado, ou seja, que é de fato o Outro que ele destrói e não seu simulacro. Faz sentindo, desse modo, pensar que dentro desse confronto existe um discurso vencedor e um malsucedido, de modo que o vencedor se estabelece quando seu discurso é permeado de argumentos reais, estando melhor estruturado.

Como já citamos anteriormente, o discurso não escapa à polêmica e, por isso, não escapa à interdiscursividade para constituir-se. Não é possível que se construa um enunciado livre de textos que já circulavam no universo discursivo, que já estavam dados, e que nos atravessam integralmente, quando se pretende elaborar um.

No próximo item, nos interessará abordar as etapas metodológicas de delimitação dos textos a serem submetidos à análise, assumindo como horizonte teórico a discussão empreendida acima.

\section{"O conteúdo dos diálogos é tão importante quanto o modo como eles foram obtidos": a constituição do corpus de análise}

Neste item, delimitaremos o corpus que submetemos à investigação, a partir das considerações teórico-metodológicas expostas anteriormente. Apenas recuperamos aqui a importância do princípio da alteridade na constituição de material para análise. A explicitação de tal princípio possui o mérito de, além de orientar as práticas de análise que se seguirão, apresentar nossa inscrição no clássico debate a respeito de uma pretensa fragilidade da $\mathrm{AD}$ em relação aos roteiros metodológicos.

Se o consideramos "clássico", isso se dá tão somente por compreendermos que, já na década de sessenta, esse debate recebeu respostas bastante consistentes de M. Pêcheux, quando observa, tal como registrou Henry (1997), que os instrumentos não são apenas utilizados pelas ciências, mas produzem efeitos de ajustamento de seu discurso: "as ciências colocam suas questões, através da interpretação de instrumentos, de tal maneira que o ajustamento de um discurso científico a si mesmo consiste, em última instância, na apropriação dos instrumentos pela teoria" (HENRY, 1997, p. 17).

Com efeito, o princípio da alteridade, a que nos referimos, pode assumir a seguinte formulação, de natureza metafórica, definindo-o como a perspectiva que afirma que "o interior de toda casa leva as marcas de seu exterior e que todo espaço íntimo se estrutura na relação com os estranhos e os importunos" (AMORIM, 2004, p. 27). Para que tal definição seja compatível com a hipótese da semântica global, será preciso considerar que o dentro e o fora da casa não corresponderiam a estados permanentes, em outras palavras, a (infra)estruturas definidas a priori, mas espaços em constante interdelimitação. 
Sem dúvida, essa perspectiva remete às contribuições do Círculo de Bakhtin, elaboradas ainda no final da década de vinte do século passado: "Na realidade, toda palavra comporta duas faces. Ela é determinada tanto pelo fato de que procede de alguém, como pelo fato de que se dirige para alguém" (BAKHTIN, 2004, p. 113). Como se vê, o princípio do direcionamento da palavra - que estabelece evidente contraposição aos modelos que repartem emissor-ativo e receptor-passivo - se desdobra na afirmação de que esse direcionamento deixa marcas nas próprias palavras. Dito de outro modo, "a situação social mais imediata e o meio social mais amplo determinam completamente e, por assim dizer, a partir do seu próprio interior, a estrutura da enunciação" (BAKHTIN, 2004, p. 113).

Em uma apropriação dessa discussão aos estudos do discurso, não haveria texto que não houvesse sido produzido originalmente em um caráter responsivo, estabelecendo relações mais ou menos explícitas com outros enunciados. Desse modo, perde-se uma pretensa dimensão naturalizante das práticas de "coletas de dados", em favor da investigação que sustenta as tensões que se elaboram em um campo de forças. Nesse sentido, essa crítica pode ser sintetizada do seguinte modo:

[...] afastamo-nos do plano das evidências empíricas, segundo o qual bastaria ir ao campo para 'coletar' um corpus já pronto, e adentramos o da construção (sempre por meio de escolhas perspectivas, interessadas, assentadas em um quadro teórico) empreendida pelo pesquisador (RODRIGUES; ROCHA, 2010, p. 212).
A respeito da seleção dos textos submetidos à análise, é possível articular com "o dado colhido em uma pesquisa já é o efeito de uma objetivação, a extremidade de um processo, forma compacta que nos dá a sensação de matéria estável, de fato acabado" (ROCHA, 2006, p. 171). Nesse contexto, parece-nos especialmente relevante a advertência de Rodrigues e Rocha:

[...] trabalhar com grandes conjuntos remetendo a posicionamentos discursivos em franca oposição não representa qualquer garantia de sucesso; pelo contrário, as grandes oposições são também aquelas que dificilmente poderíamos operacionalizar em procedimentos de análise consistentes (2010, p. 213).

No que tange à seleção de textos, partiu-se do interesse por compreender os sentidos em disputa em torno do impeachment. Nessa direção, a explicitação das etapas demonstra o tipo de investimento na composição do debate que se realizou. A primeira etapa expõe a temática definida a ser explorada. $\mathrm{Na}$ sequência, procedeu-se a uma busca preliminar na página eletrônica Google, marcando a opção por notícias ${ }^{1}$. No entanto, ao lado do conjunto de notícias inicialmente apresentado, duas colunas pareciam compor uma interessante arena de embates.

A curiosidade estava marcada desde a observação dos títulos: "Impeachment" (Anexo 1) e "A mentira do golpe" (Anexo 2). Se, nas manifestações de rua, as oposições pareciam se sintetizar nos itens "impeachment" x "golpe", nos artigos que 
nos chamavam a atenção esses itens já apresentavam, de saída, uma reelaboração, evidenciando as citações de posicionamentos contrários. Ao contrário do que sugeriria a menção ao "impeachment", não se garante que o ponto de vista sustentado no texto entre em convergência com o anúncio proposto pelo título. De maneira distinta, no texto 2 , o elemento "golpe" é inserido em sintagma nominal que apresentava uma avaliação que desqualifica tal perspectiva.

Outro dado importante para o tipo de análise proposto reside em observar os perfis dos autores dos dois textos. $\mathrm{O}$ primeiro deles é Marcelo Freixo, reeleito deputado estadual, em 2014, no Rio de Janeiro, cujo partido produziu uma linha argumentativa que sustentava críticas às opções econômicas do governo Dilma-Temer e, ao mesmo tempo, manifestava explicitamente posição contrária ao que se denominou golpe. O segundo é Aécio Neves, eleito senador em 2010, pelo estado de Minas Gerais, e adversário da chapa Dilma-Temer, nas eleições presidenciais de 2014. Sua posição a respeito do processo em curso recusava a denominação golpe e sustentava a existência de um processo pretensamente legítimo em curso. Uma descrição prévia das posições de seus autores indica uma situação bastante curiosa: a despeito do que se viu cristalizar no período de duração do processo de impeachment na cena midiática, não se observa, no arranjo de textos a ser submetido à análise, um alinhamento, dois a dois, entre posições relativas ao governo e posições relativas ao processo de impeachment. Essa quebra de expectativas em relação aos alinhamentos que se cristalizaram parece destacar mais um elemento de produtividade do referido material.

\section{"Democracia não combina com salvadores da pátria": análise da construção dos embates}

Neste item, apresentaremos as análises do material descrito anteriormente, a partir do levantamento que realizamos dos vestígios linguísticos presentes na organização interna de cada texto. Nesse levantamento, consideramos os vestígios que permitem restituir o cenário de embates constituídos entre os posicionamentos em questão. Ressaltamos, nesse sentido, que o posicionamento construído em cada texto reivindica sua legitimidade de dizer a partir de um conjunto de alianças que se deixam perceber na materialidade e também anunciam contra que elementos investem suas lutas.

Dessa maneira, o interesse dos analistas do discurso recai sobre o modo como cada posicionamento delimita a arena de embates nas quais se inscreve. No caso específico do material submetido à análise, observamos que não são apenas argumentos que estão apresentados em contraposição sobre um mesmo tema. É a própria possibilidade de construir uma rede de temáticas que está em jogo, 
definindo-se em inscrições históricas distintas, apresentando atores sociais envolvidos e redefinindo seus papéis.

Iniciaremos nossas considerações de análise, por ordem cronológica de publicação dos textos. Isto posto, começaremos pelo artigo intitulado "Impeachment”, de Marcelo Freixo. Já no primeiro parágrafo, duas pistas se evidenciam, demonstrando sua produtividade na construção de efeitos de sentido. São elas a variação no emprego de pessoas e o uso da negação. Em relação ao emprego das pessoas, observa-se o deslocamento entre os dois fragmentos destacados:

F1: "Faço uma apologia ao diálogo"

F2: "Não ergamos muros"

Em F1, a primeira pessoa do singular realiza uma conjugação entre dizer e mostrar-se dizendo, em enunciado que exibe também em seu conteúdo aquilo que ele realiza. Dessa forma, essa reiteração do que se realiza como ato de enunciação e o conteúdo do enunciado, assumido no singular com "faço", confere ao texto um tom de assertividade. Tal convocação se desdobrará em F2: "Não ergamos muros". Se a "apologia" se realiza como uma ação afirmativa do enunciador, sua efetuação se apresenta como responsabilidade compartilhada por um "nós".

No mesmo parágrafo, outra marca linguística saliente indica a produtividade da negação, em especial da negação polêmica (DUCROT, 1987). Para se ter ideia de sua importância no texto 1, en- contramos 12 ocorrências, quantidade que consideramos bastante significativa. Apresentamos abaixo as duas primeiras ocorrências, localizadas no primeiro parágrafo e numeradas de acordo com sua ordem de aparição neste texto:

F3: "O mundo não pode ser dividido em coxinhas e petralhas".

F2: "Não ergamos muros".

Seguindo o procedimento proposto originalmente por Ducrot (1987) e em consonância com o investimento discursivo apresentado em Rodrigues (2002), Rodrigues e Sampaio (2008) e Rodrigues e Rocha (2010), considera-se que "dizer não significa negar o conteúdo que o ponto de vista de um outro poderia assumir, travando-se um diálogo sub-reptício" (RODRIGUES; ROCHA, 2010, p. 216). Esse diálogo se explicita pela possibilidade de recuperar, nos enunciados negativos, um ponto de vista afirmativo subjacente. De acordo com essa orientação, no trecho "A crença no salvacionismo judiciário é perigosa porque tolera arbitrariedades e reflete não apenas o completo esvaziamento da política, mas a sua total negação", a negação é parte da estrutura "não apenas... mas também".

Recorrendo à perspectiva enunciativa, podemos atribuir às ocorrências destacadas os pontos de vista subjacentes seguir.

Ponto de vista afirmativo em F3: O mundo pode ser dividido em coxinhas e petralhas. 
Ponto de vista afirmativo em F2: Ergamos muros / Podemos erguer muros.

Procedemos à explicitação das afirmações subjacentes:

F4: "Não é possível que as pessoas contrárias ao impeachment ou que criticam as atitudes do juiz Sergio Moro, apesar da gravidade de todas as denúncias contra o governo, sejam simploriamente acusadas de defenderem a corrupção".

Ponto de vista afirmativo: as pessoas contrárias ao impeachment ou que criticam as atitudes do juiz Sergio Moro [apesar da gravidade de todas as denúncias contra o governo] podem ser [simploriamente] acusadas de defenderem a corrupção

F5: "O combate à corrupção é fundamental, mas não pode ferir regras básicas do Estado democrático de Direito".

Ponto de vista afirmativo: [O combate à corrupção] pode ferir regras básicas do Estado democrático de Direito.

F6: "As investigações não podem ser empurradas pela lógica do "custe o que custar", violando os limites legais".

Ponto de vista afirmativo: as investigações podem ser empurradas pela lógica do "custe o que custar".

F7: "Por mais importantes que sejam as investigações da Lava Jato e por maior que seja o clamor popular, as instituições não podem agir sob o calor dos acontecimentos e atropelar os ritos legais em nome do combate à corrupção"

Ponto de vista afirmativo: as instituições podem agir sob o calor dos acontecimentos
F8: "Não é pelo governo, é pela democracia".

Ponto de vista afirmativo: é pelo governo.

F9: "As ruas são o espaço da política e das nossas diferenças, mas as instituições não podem funcionar sob o ímpeto da mesma lógica"

Ponto de vista afirmativo: as instituições podem funcionar sob o ímpeto da mesma lógica [política das ruas e das nossas diferenças].

F10: "A democracia não é construída com heróis, mas com instituições fortes e equilibradas que funcionem de forma soberana e transparente e que atuem dentro dos limites das garantias constitucionais"

Ponto de vista afirmativo: A democracia não é construída com heróis.

F12: "O messianismo pode ser sedutor aos espíritos cansados, mas não nos conduzirá ao paraíso"

Ponto de vista afirmativo: O messianismo nos conduzirá ao paraíso

F13: "A resposta para a crise não é judicialização, mas a reafirmação da política enquanto espaço do diálogo, do convívio da diferença e da construção pública”.

Ponto de vista afirmativo: A resposta para a crise não é judicialização.

F14: "Democracia não combina com salvadores da pátria".

Ponto de vista afirmativo: Democracia não combina com salvadores da pátria. 
A partir da atribuição de pontos de vista subjacentes, consideramos ser possível delimitar, ao menos, três perfis de enunciadores:

\section{Enunciador divisionista:}

O mundo pode ser dividido em coxinhas e petralhas

Ergamos muros / Podemos erguer muros

As pessoas contrárias ao impeachment ou que criticam as atitudes do juiz Sergio Moro [apesar da gravidade de todas as denúncias contra $o$ governo] podem ser [simploriamente] acusadas de defenderem a corrupção É pelo governo

\section{Enunciador arrivista:}

[O combate à corrupção] pode ferir regras básicas do Estado democrático de Direito

As investigações podem ser empurradas pela lógica do "custe o que custar" As instituições podem agir sob o calor dos acontecimentos

As instituições podem funcionar sob o ímpeto da mesma lógica [política das ruas e das nossas diferenças]

A resposta para a crise é judicialização

\section{Enunciador ingênuo:}

A democracia é construída com heróis O messianismo nos conduzirá ao paraíso

Democracia combina com salvadores da pátria
Essa explicitação da distribuição dos perfis de enunciadores convocados ao debate no referido texto fornece uma perspectiva bastante interessante não apenas da maneira que é possível qualificar as tensões em jogo, mas principalmente viabiliza uma compreensão a respeito do modo de construção da arena de debates. Essa construção se realiza pela convocação exaustiva de pontos de vista diversos do enunciador, introduzidos sem uma exploração de avaliações prévias. Opta-se por um trabalho de captação das diferentes vozes em jogo, muito mais do que o fornecimento de julgamentos de valor acerca dessa construção.

Explorando, ainda que minimamente, o trabalho de variação das referências de pessoa teríamos os quatro enunciados a seguir, nos quais o emprego da primeiro pessoa do plural inclui o enunciador e 0 público, de um modo geral:

F15: "Nossa democracia é uma conquista recente que custou muito caro. Enfrentamos o chumbo de oito anos de Estado Novo e 21 anos de ditadura civil-militar".

F16: “Todos somos responsáveis pela preservação do Estado democrático de Direito".

F17: "Precisamos criar formas de baratear campanhas eleitorais, acabar com 0 sequestro da soberania pela oligarquia político-econômica, fortalecer a transparência e garantir a participação das pessoas nas decisões de interesse comum".

F18: "O futuro cabe a nós mesmos". 
No texto 2, de Aécio Neves, a elaboração do ponto de vista sustentado parece recorrer a procedimentos bastante distintos do observado no texto 1 . Em vez de haver a exploração de uma ou duas marcas linguísticas de maneira mais intensa, o que ganha destaque, à primeira vista, nesse texto é o emprego alternado de enunciados mais longos com outros mais curtos. Nesse sentido, os dois primeiros parágrafos demonstram tal articulação:

F1: "A presidente da República, o PT e os aliados do atual governo prestam um enorme desserviço à Nação ao comparar a luta atual contra a corrupção e a favor do impeachment com o movimento golpista que há 52 anos tomou o poder e nos impôs um longo período de trevas. Esta é uma farsa grotesca contra a qual é preciso reagir".

F2: "Não há como comparar os idos de 1964 com o estado de normalidade democrática que vivenciamos hoje. Ao adotar a estratégia de terror para assustar a Nação e ameaçar a oposição, sustentada em uma retórica cada vez mais incendiária, a presidente atropela a história, incita a intolerância e afronta as instituições que zelam pela democracia".

Em F1, o enunciador enumera, em sequência, os atores sociais contra os quais se insurge: "A presidente da República", "o PT" e "os aliados do atual governo". Apresenta ainda, em um longo trecho, a citação de um discurso atribuído a esses atores, introduzido pelo elemento "com- parar". O trecho mais curto apresenta explicitamente uma avaliação - "uma farsa grotesca", encadeada ao parágrafo como denúncia - "esta é" - em relação à qual o enunciador realiza uma convocação - "é preciso reagir".

Em F2, reitera-se o que havia sido mencionado no parágrafo anterior, construindo a tensão entre "compara" x "não há como comparar". Nesse parágrafo, como se pode observar, a sequência de orações mais curtas é desdobrada - "a presidente atropela a história", "[a presidente] incita a intolerância e "[a presidente] afronta as instituições [que zelam pela democracia]"

No quarto e no quinto parágrafos, os procedimentos de citação de outras vozes passam a introduzir vozes que estabelecem aliança com o ponto de vista sustentado pelo enunciador:

F3: "Os juristas Miguel Reale Jr., ex-ministro da Justiça, e Janaína Paschoal, autores do pedido de impeachment da presidente, em audiência na Câmara, semana passada, sustentaram que sobram crimes de responsabilidade capazes de justificar a interrupção do mandato presidencial. Citaram as manobras fiscais que infringiram gravemente e de forma continuada a Lei de Responsabilidade Fiscal, os ilícitos orçamentários e a omissão não explicada da chefe de Estado frente ao maior esquema de corrupção da história do país, que sangrava a nossa principal estatal"

Em F3, a citação é introduzida por "sustentaram", seguido por uma estrutura oracional que apresentaria o conteúdo 
da fala em relato. Nessa estrutura, são explicitados elementos que, possivelmente, remeteriam à fala dos "juristas", dada a vinculação que estabelecem com certo grau de formalidade, tais como "crimes de responsabilidade" e "interrupção do mandato presidencial”. A ela mesclam-se elementos que simulam um emprego mais informal da língua, tal como "sobram". Na sequência, um novo relato é introduzido por "citaram", seguido de uma enumeração de elementos que igualmente incorporam contornos formais que se atualizam tanto no emprego de expressões técnicas, quanto no uso de letra maiúscula, delimitando as instituições: "Lei de Responsabilidade Fiscal" e "Estado".

F4: "Infelizmente, os fatos corroboram a afirmação feita por Janaína de que 'a responsabilidade fiscal não é um valor para este governo'. Um governo que abusou de artifícios fiscais à revelia dos procedimentos fixados pela Constituição e promoveu um ataque frontal aos alicerces da Lei de Responsabilidade Fiscal, este verdadeiro patrimônio institucional do país. É contra este abuso de poder que precisamos reagir. Golpe mesmo foi a fraude eleitoral protagonizada pelo governo, ao criar na população o sentimento de que existia uma segurança financeira e fiscal para cumprir todas aquelas promessas de campanha. Já era sabido pela presidente candidata que ela que não teria como cumpri-las. Mentiram sabendo que mentiam"

À semelhança do que se observou nas ocorrências anteriores, procedimentos de avaliação estão explicitamente presen- tes, marcando, no plano do dito, a perspectiva introduzida pelo enunciador. Em F2, o enunciador avalia a aliança entre "fatos" e a "afirmação feita por Janaína" com o elemento "infelizmente", mesmo que tal aliança corresponda ao projeto de argumentação estabelecido desde o início do texto. Na sequência, um trecho atribuído à "Janaína" é introduzido entre aspas: 'a responsabilidade fiscal não é um valor para este governo'. Repetindo procedimento anterior, o emprego de letras maiúsculas sugere aliança entre "Lei de Responsabilidade Fiscal" e "Constituição", como instituições consolidadas e em oposição aos atores que o enunciador apresenta como seus adversários. De igual maneira, repete-se a convocação à reação: "É contra este abuso de poder que precisamos reagir". Como se observa, os procedimentos adotados se repetem ao longo do texto, caracterizando um enunciador que se expressa por sequências e procedimentos que se repetem e, ao mesmo tempo, atualizam sua avaliação explicitamente na superfície verbal, sugerindo uma imagem de leitor com certa predileção pelo dito/visível efetivamente realizado.

\section{Considerações finais: "o futuro cabe a nós mesmos"}

No presente texto, investigamos a formação de posicionamentos em embate acerca do processo de impeachment. Consideramos, para isso, a importância 
que atribuímos ao investimento realizado por diversas áreas do conhecimento na compreensão desse processo histórico que ainda se reelabora, que altera substancialmente os contornos da história brasileira contemporânea.

Ao proceder nessa direção, afirmamos a condição de cientista social implicada na atividade do linguista, fornecendo conceitos e encaminhamentos que possibilitem uma leitura crítica do entorno, em especial de um evento que ainda merece muita reflexão e compreensão de sua gênese social e avaliação de seus desdobramentos ainda em curso.

A perspectiva enunciativa adotada permitiu compreender a construção das arenas de debate, a partir de procedimentos linguístico-discursivos bastante diversos. O projeto do referido levantamento de pistas mais salientes se organiza a partir da premissa de que um texto jamais se reduziria ao conteúdo manifesto, mas se constitui de acordo com uma rede de coerções que se atualizam em diferentes dispositivos.

$\mathrm{Na}$ análise empreendida, encontramos modos distintos de se apropriar dos diferentes dispositivos que compõem e integram os posicionamentos em embate. Entre os resultados obtidos, destaca-se uma distinção no trabalho com as vozes que habitam o debate a respeito do $\mathrm{im}$ peachment. No artigo que se encontra o posicionamento contrário ao processo de impeachment, o enunciador põe em jogo pontos de vista diversos, que se manifestam pelo uso recorrente da negação polêmica. Simultaneamente, realiza-se uma aproximação em relação não apenas ao leitor, mas ao público, de um modo geral, distribuindo com todos a responsabilidade pela construção democrática, compondo um posicionamento mediador-responsável. Já no texto em que se sustenta posicionamento favorável ao impeachment, a organização textual parece fornecer pistas a partir de uma alternância entre estruturas frasais mais longas e estruturas mais curtas. Tais estruturas comportam uma articulação entre acusação e convocação à reação, contribuindo a construção de um posicionamento reativo-acusatório.

"The world can not be divided between coxinhas and petralhas": the construction of positioning around impeachment

\section{Abstract}

The process of impeachment carried out in 2016 convokes many areas of knowledge to a critical reflection and some problematizations of its emergence and consolidation. In order to provide a contribution to the reading of this process, we interrogate the construction of discursive positions around this event that significantly changes the contours of contemporary Brazilian history. As a theoretical framework, we appeal to the analysis of enunciative discourse, whose focus falls on the way of articulating linguistic-discursive clues in the reconstruction of the clashes from whi- 
ch the positions are constructed. In our analysis, we look into two opinion piece published in a vehicle of great circulation in the country, before the final vote in the Federal Senate. As results, we highlight the different lines that constitute the positions at stake, indicating that, on the opposite side, there are perspectives that promote dialogue between different points of view and, on the favorable side, unilateral oppositions are concentrated.

Keywords: impeachment; coup d'etat; positioning; discourse analysis.

\section{Nota}

1 Um maior detalhamento a respeito do universo de textos levantado inicialmente encontra-se em Gesteira (2017).

\section{Referências}

AMORIM. M. O pesquisador e seu outro: Bakhtin nas Ciências Humanas. São Paulo: Musa, 2004.

DUCROT, O. O dizer e o dito. Campinas: Pontes, 1987.

GESTEIRA, P. Análise discursiva de notícias sobre a admissibilidade do processo de impeachment veiculadas nas cidades de São Paulo e Salvador. 2017. Dissertação (Mestrado em Letras), Rio de Janeiro, Universidade do Estado do Rio de Janeiro.

HENRY, P. Os fundamentos teóricos da 'análise automática do discurso' de Michel Pêcheux. In: GADET, F.; HAK, T. (Org). Por uma análise automática do discurso: uma introdução à obra de Michel Pêcheux. Trad. Bethania S. Mariani et al. Campinas: Editora da Unicamp, 1997.

MAINGUENEAU, D. Gênese dos discursos. Trad. de Sírio Possenti. Curitiba: Criar, 2005.
. Novas Tendências em Análise do Discurso. Trad. de Freda Indursky. Campinas: Ponte; Ed. da Unicamp, 1997.

ORLANDI, E. P. Análise de Discurso: princípios e procedimentos. Campinas: Pontes, 2005.

POSSENTI, S. Teoria do discurso: um caso de múltiplas rupturas. In: MUSSALIM, F.; BENTES, A. C. (Org) Introdução à Linguística. vol. 3. São Paulo: Cortez, 2003, p. 353-391.

ROCHA, D.; DEUSDARÁ, B. Dispositivos da Análise Institucional para a explicitação da dimensão política das práticas discursivas. Moara. V. 47, n. 1, 2017, p. 108-127. Disponível em: http://www.periodicos.ufpa.br/index. $\mathrm{php} / \mathrm{moara} /$ article/view/5281/4452. Acesso em: 14 fev. 2017.

ROCHA, D.; DEUSDARÁ, B. Análise de conteúdo e análise do discurso: o linguístico e seu entorno. DELTA, v. 22, p. 29-52, 2006.

ROCHA, D.; DEUSDARÁ, B. Análise de Conteúdo e Análise do Discurso: aproximações e afastamentos na (re)construção de uma trajetória. Alea: Estudos Neolatinos, v. 7, p. 305-322, 2005.

RODRIGUES, I. C.; ROCHA, D. Implicações de uma perspectiva discursiva para a construção de uma metodologia de análise das práticas linguageiras. Gragoatá, Niterói, n. 29, v. 2, p. 205-222, 2010. Disponível em: http://www.gragoata.uff.br/index.php/ gragoata/article/view/172/156 Acesso em: 21 fev. 2018.

RODRIGUES, I. C. Debates em educação bilíngue para surdos: vozes que habitam o dizer não. Dissertação (Mestrado). 2002. Rio de Janeiro, Universidade do Estado do Rio de Janeiro.

SAMPAIO, F. de A. O que (não) é um RPG: polêmica e produção de sentidos em discursos sobre o role playing game. Dissertação (Mestrado). 2008. Rio de Janeiro, Universidade do Estado do Rio de Janeiro. 


\section{Anexo 1 Impeachment}

\section{Marcelo Freixo}

Faço uma apologia ao diálogo. O mundo não pode ser dividido em coxinhas e petralhas. Não ergamos muros. Muros são surdos e podem soterrar a democracia.

Não é possível que as pessoas contrárias ao impeachment ou que criticam as atitudes do juiz Sergio Moro, apesar da gravidade de todas as denúncias contra o governo, sejam simploriamente acusadas de defenderem a corrupção.

O combate à corrupção é fundamental, mas não pode ferir regras básicas do Estado democrático de Direito. As investigações não podem ser empurradas pela lógica do "custe o que custar", violando os limites legais.

Nossa democracia é uma conquista recente que custou muito caro. Enfrentamos o chumbo de oito anos de Estado Novo e 21 anos de ditadura civil-militar. Todos somos responsáveis pela preservação do Estado democrático de Direito.

Por mais importantes que sejam as investigações da Lava Jato e por maior que seja o clamor popular, as instituições não podem agir sob o calor dos acontecimentos e atropelar os ritos legais em nome do combate à corrupção. Não é pelo governo, é pela democracia.

Todas as manifestações são legítimas, sejam de esquerda ou direita, verdes, amarelas ou vermelhas. As ruas são o espaço da política e das nossas diferenças, mas as instituições não podem funcionar sob o ímpeto da mesma lógica.

É preocupante ver um juiz trocar a toga pela carapuça de herói nacional e extrapolar as exigências de seu cargo, publicando notas de caráter político, autorizando e divulgando escutas telefônicas juridicamente questionáveis e vazando informações de forma seletiva.
O conteúdo dos diálogos é tão importante quanto o modo como eles foram obtidos.

A democracia não é construída com heróis, mas com instituições fortes e equilibradas que funcionem de forma soberana e transparente e que atuem dentro dos limites das garantias constitucionais.

A crença no salvacionismo judiciário é perigosa porque tolera arbitrariedades e reflete não apenas o completo esvaziamento da política, mas a sua total negação.

O messianismo pode ser sedutor aos espíritos cansados, mas não nos conduzirá ao paraíso. A resposta para a crise não é judicialização, mas a reafirmação da política enquanto espaço do diálogo, do convívio da diferença e da construção pública.

Precisamos criar formas de baratear campanhas eleitorais, acabar com o sequestro da soberania pela oligarquia político-econômica, fortalecer a transparência e garantir a participação das pessoas nas decisões de interesse comum.

Democracia não combina com salvadores da pátria. Como dizia o dramaturgo alemão Bertolt Brecht, pobre do povo que precisa de heróis. $\mathrm{O}$ futuro cabe a nós mesmos.

Publicado originalmente em Folha de São Paulo, 22/03/2016

Disponível em: http://www1.folha.uol. com.br/colunas/marcelo-freixo/2016/03/

1752613-impeachment.shtml

\section{Anexo 2 A mentira do golpe}

Aécio Neves

A presidente da República, o PT e os aliados do atual governo prestam um enorme desserviço à Nação ao comparar a luta atual contra a corrupção e a favor do impeachment com o movimento golpista que há 52 anos tomou o poder e nos impôs um longo período 
de trevas. Esta é uma farsa grotesca contra a qual é preciso reagir.

Não há como comparar os idos de 1964 com o estado de normalidade democrática que vivenciamos hoje. Ao adotar a estratégia de terror para assustar a Nação e ameaçar a oposição, sustentada em uma retórica cada vez mais incendiária, a presidente atropela a história, incita a intolerância e afronta as instituições que zelam pela democracia.

O Brasil vive um momento de inquietação política que requer serenidade de todos nós. Os ânimos estão acirrados, sem dúvida. No entanto, devemos reconhecer que as instituições permanecem sólidas, funcionando em sua plenitude. Em respeito à memória histórica, lembremos que em 1964 houve uma clara ruptura institucional. Ou seja, o discurso do golpe já nasce contaminado pela mentira.

Os juristas Miguel Reale Jr., ex-ministro da Justiça, e Janaína Paschoal, autores do pedido de impeachment da presidente, em audiência na Câmara, semana passada, sustentaram que sobram crimes de responsabilidade capazes de justificar a interrupção do mandato presidencial. Citaram as manobras fiscais que infringiram gravemente e de forma continuada a Lei de Responsabilidade Fiscal, os ilícitos orçamentários e a omissão não explicada da chefe de Estado frente ao maior esquema de corrupção da história do país, que sangrava a nossa principal estatal.

Infelizmente, os fatos corroboram a afirmação feita por Janaína de que "a responsabilidade fiscal não é um valor para este governo". Um governo que abusou de artifícios fiscais à revelia dos procedimentos fixados pela Constituição e promoveu um ataque frontal aos alicerces da Lei de Responsabilidade Fiscal, este verdadeiro patrimônio institucional do país. É contra este abuso de poder que precisamos reagir. Golpe mesmo foi a fraude eleitoral protagonizada pelo governo, ao criar na população o sentimento de que existia uma segurança financeira e fiscal para cumprir todas aquelas promessas de campanha. Já era sabido pela presidente candidata que ela que não teria como cumpri-las. Mentiram sabendo que mentiam.

Os brasileiros que acreditaram nas quimeras de campanha hoje enfrentam a duríssima realidade de inflação alta, desemprego galopante, enfraquecimento dos programas sociais e uma profunda recessão. Os mineiros sabem isso.

Lutar contra este estado de coisas e apontar os crimes de responsabilidade ocorridos não é pregar um golpe, muito ao contrário. Não existe golpe quando se cumpre a Constituição. Não existe golpe quando o Supremo Tribunal Federal avaliza e determina o rito a ser seguido. Apenas nos regimes totalitários há salvo-conduto para um governante.

No ambiente atual, não existe qualquer ameaça de ruptura institucional. Quem quer desestabilizar a normalidade democrática e colocar em suspeição o trabalho das instituições republicanas são os arautos deste falso golpe. Este sim, um atentado contra o Estado de Direito que a sociedade brasileira construiu tão duramente ao longo dos últimos anos.

Publicado originalmente em: Jornal Estado de Minas, 02/04/2016. Disponível em formato eletrônico em: http://aecioneves.com.br/sala-de-imprensa/ artigos/a-mentira-do-golpe/ 